\title{
EDUCAÇÃO SUPERIOR E FORMAÇÃO DE PROFESSORES: INOVAÇÕES E DESAFIOS
}

\author{
EDUCACIÓN SUPERIOR Y FORMACIÓN DE DOCENTES: \\ INNOVACIONES Y RETOS
}

\section{HIGHER EDUCATION AND TEACHERS TRAINING: INNOVATIONS AND CHALLENGES}

Andréia Morés ${ }^{1}$

RESUMO: Este artigo contempla algumas reflexões sobre educação superior e formação de professores, realizadas em uma pesquisa vinculada ao Observatório de Educação. Foram investigadas as inovações presentes nos Cursos de Pedagogia de uma universidade comunitária do Rio Grande do Sul. A metodologia contemplou a abordagem qualitativa, referendada por Bogdan e Biklen (1994), com ênfase no método Estudo de Caso, seguindo os estudos de Yin (2015). Os resultados apontam a relevância de a universidade investir na formação de professores, potencializando a inovação, a pesquisa, a articulação teoria e prática, a vivência nos estágios e a aproximação com a realidade educacional e social. Portanto, destaca-se a relevância de uma visão institucional que vise à formação humana, a construção e a socialização do conhecimento, vinculadas aos princípios emancipatórios e democráticos.

PALAVRAS-CHAVE: Educação superior. Curso de pedagogia. Inovação.

RESUMEN: En este artículo se contemplan algunas reflexiones acerca de la educación superior y la formación de docentes, según fueron realizadas en una investigación relacionada al Observatorio de Educación. Se investigaron las innovaciones presentes en los Cursos de Pedagogía presenciales y a distancia de una universidad comunitaria del estado brasileño de Rio Grande do Sul. La metodología contempló el abordaje cualitativo, tomando como referencia a Bogdan y Biklen (1994), con énfasis en el método Estudio de Caso según los estudios de Yin (2015). Los resultados muestran la relevancia de la Universidad invertir en la formación de docentes, potencializando la innovación, la investigación, la articulación entre la teoría y la práctica, la vivencia en las prácticas y el acercamiento a la realidad educacional y social. Por ende, se destaca la relevancia de una visión institucional destinada a la formación humana, la construcción y la socialización del conocimiento, vinculadas a los principios emancipatorios y democráticos.

PALABRAS CLAVE: Educación superior. Curso de pedagogía. Innovación.

\footnotetext{
${ }^{1}$ Universidade de Caxias do Sul (UCS), Caxias do Sul - RS - Brasil. Professora na Área do Conhecimento de Humanidades, Professora do Programa de Pós-Graduação em Educação (PPGEdu/UCS). Doutora em Educação. ORCID: http://orcid.org/0000-0002-6982-0803. E-mail: anmores18@hotmail.com
} 
ABSTRACT: This article considers a few thoughts about higher education and teachers training carried out in a research connected with the Education Observatory. The investigations focused on the innovations present in on-line and distance learning Pedagogy Courses of a community university from Rio Grande do Sul. The methodology contemplated the qualitative approach, supported by Bogdan and Biklen (1994), with emphasis on the Case Study method according with the studies of Yin (2015). Findings point out the relevance of the University investment in the education of teachers by maximizing innovation, research, articulation between theory and practice, internship experience and the approximation with the educational and social reality. Thus, it is highlighted the emphasis of an institutional view aiming at the human education, the construction and socialization of knowledge, in connection with emancipatory and democratic principles.

KEYWORDS: Higher education. Pedagogy program. Innovation.

\section{Introdução}

O presente texto contempla estudos e reflexões referentes a uma investigação sobre a formação de professores na universidade realizada pelo Observatório de Educação, com destaque ao processo formativo e investigativo vivenciado junto ao curso de Licenciatura em Pedagogia de uma universidade comunitária, com mais de 50 anos de experiência sobre formação de professores. Observam-se avanços em relação às políticas educacionais, mais especificamente nas Diretrizes Curriculares Nacionais, conforme a Resolução n. 2, de $1^{\circ}$ de julho de 2015 (BRASIL, 2015), quando preconizam que a formação docente deve ser um processo dinâmico e complexo, contemplando a qualidade social da educação e a valorização profissional. Assim, destaca-se a importância de estudos e pesquisas que investiguem esse cenário de formação docente.

Para referendar a educação superior e a formação de professores tem-se por base autores que são referência nacional e internacional, principalmente Santos (2004), Nóvoa (2017), Freire (1991, 2013) Arroyo (2004), Franco, Libâneo e Pimenta (2011, p. 64), defensores de uma formação articulada com os contextos e as experiências vividas pelos estudantes, em prol da reflexão, do diálogo e da pesquisa e inovação. Para embasar a inovação pedagógica e tecnológica inserem-se os autores Cunha (2016), Leite (2012), Kenski (2012), Morosini et al., (2016), Pretto e Pinto (2006), que corroboram a compreensão da inovação enquanto ruptura epistêmica vivida na ciência moderna e adentram em uma visão social, humana e educacional da inovação pedagógica e tecnológica.

O presente artigo abrange estudos e reflexões sobre a formação de professores na universidade. $\mathrm{O}$ processo metodológico da presente investigação contempla a metodologia qualitativa, referendada por Bogdan e Biklen (1994), com ênfase no método estudo de caso, 
conforme Yin (2015). A construção dos dados abarcou a análise de documentos institucionais e os depoimentos dos estudantes dos Cursos de Pedagogia de uma universidade comunitária do Rio Grande do Sul.

\section{Educação superior e formação de professores}

A temática discutida neste artigo visa contribuir para a formação de professores na universidade, a fim de fortalecer esse cenário que, às vezes, se torna refém de um mercado que preconiza uma formação rápida e aligeirada. Esse cenário é observado no Brasil quando se constata o crescente mercado de instituições mercadológicas com forte ênfase na formação rápida para o mercado de trabalho.

Santos (2004) enfatiza que, a partir dos anos 1980, o neoliberalismo se impôs ao modelo global de capitalismo, e a autonomia da universidade ficou à mercê da privatização do ensino superior, acarretando uma crise nas universidades públicas e universidades privadas sem fins lucrativos, reconhecidas como universidades comunitárias (BRASIL, 2013)2 . De outro lado, no entendimento de Santos (2004), há o crescimento da globalização mercantil da universidade.

$\mathrm{Na}$ concepção de Santos, essa visão mercadológica e produtivista desvirtua a universidade e seus objetivos, e, em alguns casos, reduz os investimentos na formação humanista e cultural. Assim, defende-se que a educação deve ocupar lugar de destaque na universidade e na sociedade. Uma educação voltada à humanização, autonomia, democracia e à emancipação, de acordo com os princípios de Freire (2013, p. 40):

[...] ao exigirem a transformação das universidades, de que resultem, de um lado, o desaparecimento da rigidez nas relações professor-aluno; de outro, a inserção delas na realidade; ao proporem a transformação da realidade mesma para que as universidades possam renovar-se; ao rechaçarem velhas ordens e instituições estabelecidas, buscando a afirmação dos homens como sujeitos de decisão, todos esses movimentos refletem o sentido mais antropológico do que antropocêntrico de nossa época.

E Freire (2013) defende a humanização, a desalienação, a educação como prática de liberdade. Assim, compreende-se a importância de a universidade ser um espaço de transformação da realidade, de criação, de libertação e de formação humana. Isso se opõe aos princípios tradicionais de ensino que defendiam a educação bancária, o professor como o

${ }^{2}$ Brasil. Lei n. 12.881/2013. Dispõe sobre a definição, qualificação, prerrogativas e finalidades das Instituições Comunitárias de Educação Superior - ICES. 
detentor do conhecimento, transmissor de um saber pronto e acabado, que zelava por valores instituídos na sociedade, defendia o acesso limitado ao ensino, voltado à classe mais favorecida, gerando a exclusão social.

Em seus estudos, Freire (1991, p. 72) declara: “educação em favor da emancipação permanente dos seres humanos, considerados como classe ou como indivíduos, [educação que] se põe como um que fazer histórico em consonância com a também histórica natureza humana, inclusive, finita, limitada”. É esta visão de educação que nos inspira ao pensar sobre a formação de professores na atualidade.

É com essa visão que se adentra nos estudos sobre a Pedagogia, como afirma Arroyo (2004, p. 226): “a pedagogia nasce quando se reconhece que essa formação, envolvendo a ideia de fabricar o mundo humano, faz parte de um projeto, uma tarefa intencional, consciente". Assim, caminha-se em defesa da Pedagogia enquanto ciência, ciência da educação, articulada com a realidade educacional e social, em defesa da emancipação dos sujeitos, em um movimento que agrega intencionalidade, emancipação, formação e prática docente. Segundo Franco, Libâneo e Pimenta (2011, p. 64), "nessa perspectiva, a Pedagogia revela-se como uma ação social de transformação e de orientação da práxis educativa da sociedade, onde desvela as finalidades político/sociais presentes no interior da práxis e reorienta ações emancipatórias para sua transformação".

Considera-se que a formação referente ao Curso de Pedagogia deve contemplar os processos pedagógicos, educativos e sociais, os quais requerem e mobilizam diversos conhecimentos, saberes e competências vinculadas ao exercício profissional docente. E em conjunto com as Diretrizes Nacionais (BRASIL, 2006) observa-se que o processo de formação do egresso do curso de Pedagogia, na contemporaneidade, desafia os currículos dos cursos a desenvolverem estudos e práticas geradoras de conhecimentos e saberes para os contextos pedagógicos e educacionais. Segundo Nóvoa (2017, p. 1.109), “[...] é necessário pensar a formação de professores como uma formação profissional universitária, isto é, como a formação para o exercício de uma profissão.[...]". Para tanto, esse processo requer maior exigência e contribuição da inovação para qualificação nos processos de formação de professores.

Os estudos teóricos que embasam a inovação referendada nesta investigação centramse em Leite (2012) Cunha (2016), Morosini (2016), os quais se voltam para uma formação apoiada em concepções científicas que propõem a ruptura das visões teóricas e práticas vivenciadas na ciência moderna. Cunha (2016, p. 87) enfatiza: “[...] a concepção de inovação como ruptura paradigmática, no contexto da educação superior e da emergência de mudanças 
nas práticas tradicionais de ensinar e aprender." Por sua vez, Morosini et al., (2016, p. 27), ao tratarem dos indicadores de qualidade da educação superior na inovação pedagógica, apontam para as "formas de ensinar-aprender que ultrapassem o modo reprodutivo positivista. [...] Superação do individualismo e compreensão da construção social do conhecimento".

Esse viés vincula-se aos estudos da inovação pedagógica, e Leite (2012, p. 35) afirma: a inovação "é a ruptura com o conhecimento 'aprontado', a-histórico e desvinculado de valoração do mundo da vida e do trabalho". Nesse movimento de ruptura com o conhecimento a-histórico, deslocado dos contextos de vida, defende-se o conhecimento como processo histórico que contribui para a formação humana e social.

Seguindo esse pensamento, Leite (2012, p. 30) afirma: "entendo que a inovação pedagógica responde ao compromisso social de formação do humano docente e do humano aluno". Assim, considera-se importante que a formação acadêmica, em especial os estágios do Curso de Pedagogia, propicie momentos de estudos, de pesquisa, de formação e de construção de novos conhecimentos e saberes; superação do individualismo e compreensão da construção social do conhecimento.

Adentra-se também nas inovações tecnológicas com base em Leite (2012, p. 30): “de certa forma, tais inovações têm caráter de inovação tecnológica e destinam-se a contribuir para ampliar as alternativas de inserção nos mercados globais. [...]. O desafio da universidade, no entanto, está em colocar ao lado da inovação tecnológica, a inovação pedagógica”. Assim, trabalha-se com ambas as inovações — pedagógicas e tecnológicas — inserindo suas contribuições no processo de formação.

De acordo com Pretto e Pinto (2006, p. 22), "as tecnologias, antes entendidas como meras extensões dos sentidos do homem, hoje são compreendidas como algo muito mais profundo, que interfere no próprio sentido da existência humana”. Observa-se a defesa das tecnologias para além do uso de seus recursos, como potencialidades humanas. Corroborando esse pensamento, Kenski (2012, p. 22) afirma que as tecnologias: "quando disseminadas socialmente, alteram as qualificações profissionais e a maneira como as pessoas vivem cotidianamente, trabalham, informam-se e se comunicam com outras pessoas e com todo o mundo". É com esse olhar que se visualizam as contribuições da inovação tecnológica e pedagógica para o processo de ensino e aprendizagem. 


\section{A construção metodológica: reflexões e inovações presentes na formação acadêmica}

A construção metodológica da presente pesquisa contempla a metodologia qualitativa em educação, embasada em Bogdan e Biklen (1994), a qual proporciona uma aproximação entre o pesquisador, o campo de investigação e os sujeitos da pesquisa.

Com base na abordagem metodológica qualitativa enfatiza-se o Estudo de Caso que propicia conhecer e examinar em profundidade o caso, em seu contexto natural, reconhecendo-se sua complexidade. Segundo Yin (2015, p. 02), "um estudo de caso investiga um fenômeno contemporâneo (o 'caso') em seu contexto no mundo real, especialmente quando as fronteiras entre o fenômeno e o contexto puderem não estar claramente evidentes".

Assim, a presente pesquisa foi desenvolvida junto ao Curso de Pedagogia de uma universidade comunitária na Serra Gaúcha. Os sujeitos da pesquisa são estudantes matriculados em disciplinas de estágios, convidados a participar de modo voluntário.

A construção dos dados foi realizada durante alguns semestres. Esse período estendido foi muito importante, pois permitiu atingir o maior número possível de estudantes. Para melhor compreensão do estudo de caso, apresenta-se, aqui, um breve histórico da instituição e seu projeto de curso e, posteriormente, incluem-se os depoimentos dos participantes da pesquisa.

A universidade comunitária estudada abrange uma área de, aproximadamente, 70 municípios, e o seu Curso de Pedagogia presencial iniciou em 1960, completando, assim, quase seis décadas de experiência na formação pedagógica e docente.

A organização curricular presente no Projeto Pedagógico do Curso de Licenciatura em Pedagogia de uma Universidade Comunitária do Rio Grande do Sul tem, por princípio: o reconhecimento da instituição educacional como organização complexa cuja função é a de promover a educação para e na cidadania; a pesquisa, a análise e a aplicação do resultado de investigações de interesse da área educacional; a participação na gestão de processos educativos, na organização e no funcionamento de sistemas e instituições de ensino; a ampliação e a inclusão das TIC em espaços de formação e atuação profissional, construindo, assim, novas redes de interação e aprendizagem (UNIVERSIDADE COMUNITÁRIA, 2014).

Para o desenvolvimento desses princípios, o Projeto Pedagógico do Curso referenda a metodologia embasada nas dimensões construtivistas, interacionistas, sociais, culturais e transcendentes. Essa escolha implica uma postura que propicia o diálogo desencadeado a partir do respeito às finalidades do curso, aos interesses e às necessidades dos estudantes, estimulando a autonomia de pensamento e a construção de aprendizagens significativas. 
Retomando-se o tema após a breve apresentação da instituição, inserem-se os depoimentos dos estudantes, os quais enriqueceram as análises deste estudo, organizadas a partir dos seguintes norteadores:

\section{a) Contribuições dos estágios para a formação docente}

Os relatos expõem experiências vividas durante o curso, permitindo um novo olhar sobre a educação e a formação. "Estão sendo experiências proveitosas, pois aprendemos a todo o momento, além de compartilhar experiências, conseguimos pôr muita coisa em prática”. (Estudante 35). Também destacam professores que contribuíram para a formação, oportunizando reflexões sobre a docência: "tive e ainda tenho experiências bastante significativas no curso de Pedagogia. O aprendizado que as disciplinas proporcionam e, principalmente, a vivência com muitos professores fantásticos - que me permitiram continuar acreditando na graduação." (Estudante 58). Esse depoimento também ressalta a aproximação da teoria com a prática e as vivências entre professores, aproximando as disciplinas, cruzando conhecimento e experiências fundamentais para a construção do docente. Nóvoa (2009) destaca que a formação docente precisa estar voltada para a reflexão das ações do professor, reflexão crítica sobre a prática e de (re)construção permanente das ações pedagógicas.

Em diversos depoimentos, os estudantes reconhecem a presença de inovações na formação docente. Relatam que a aula é construída e mobilizada por ações pedagógicas, em que o aluno participa da construção do conhecimento e seu saber é valorizado; há a presença das pesquisas e da busca por materiais de apoio didático, a fim de que sejam mais dinâmicas e do interesse dos alunos. "Já realizei dois estágios, houve sim inovações, desde o envolvimento com as pesquisas e busca de materiais de apoio, para um olhar mais pedagógico na hora da atuação docente" (Estudante 46), e, além disso, "há inovação porque foram experiências novas para mim. Procurei na minha prática, buscar novas formas de trabalhar conteúdos rotineiros, mas de formas contextualizadas, significativas e que valorizem o aluno". (Estudante 46). Há destaque para o trabalho pedagógico que contemple a pesquisa, que valorize o aluno, e que, além de refletir sobre a prática docente, contribua muito para o crescimento durante os estágios. Assim, reiteram Pimenta (2004), que o estágio seja realizado com e como pesquisa.

Desse modo, enfatiza-se que o conhecimento não é produto acabado, as respostas únicas e certas perdem o sentido, havendo um distanciamento do paradigma moderno. Ao se avançar, assim, para a compreensão do conhecimento em movimento, o conhecimento é sempre passível de indagações e problematizações, em que as perguntas e dúvidas devem ser 
expressas e valorizadas, como relata o estudante a seguir: "Já realizei os quatro estágios e durante eles, percebo que em cada um fui inovando minhas práticas e aprimorando minhas ideias, sempre havia espaço para novos questionamentos e problematizações”. (Estudante $85)$.

Em consonância com esse depoimento, há relatos coletivos afirmando que, durante os momentos de orientação de estágio na universidade, conta-se com o apoio dos professores para a compreensão da realidade educacional e construção de novas práticas: "Acredito que a partir do estágio conseguimos enxergar com outros olhos os ambientes em que se dá a educação - considero os estágios de extrema importância para a formação completa de um pedagogo." (Estudante 58).

Uma fala unânime entre os estudantes é de que os estágios geram desafios e, por isso, requerem inovações. Essas inovações são realizadas durante as práticas pedagógicas desenvolvidas, e durante essas práticas os alunos começam a se sentir mais à vontade perante a futura atuação profissional: "É durante esse tempo do estágio que se percebe mais evidentemente a relação da teoria estudada ao longo do curso com a prática desenvolvida em sala de aula." (Estudante 87).

Pimenta (2012), em seus estudos, defende a aproximação da relação teoria e prática, destacando que a teoria investiga a prática "sobre a qual retroage mediante conhecimentos adquiridos. A prática [...] seria o ponto de partida do conhecimento, a base da teoria e, por efeito desta, torna-se prática orientada conscientemente". (PIMENTA, 2012, p. 113).

Assim, teoria e prática estão entrelaçadas, uma complementa a outra, sendo que a teoria proporciona suporte para a prática denominada por Pimenta (2012) de "prática orientada conscientemente". Como relata um estudante, "no estágio você acaba se empolgando nas práticas e vendo os resultados de toda a teoria que foi aprendida durante o Curso. No estágio IV, por exemplo, percebi mudanças nas próprias ações da escola durante e após a minha prática”. (Estudante 68). Destaca-se, assim, a importância de uma formação que proporcione estudos relacionados à prática, aproximando os estudantes da realidade estudada e investigada, propiciando inovações que contribuam para o cotidiano da educação.

\section{b) Inovações pedagógicas e inovações tecnológicas}

Os depoentes afirmam que as inovações pedagógicas e tecnológicas facilitam o aprendizado, favorecendo a maior compreensão do curso. Enunciam também que as inovações presentes durante a formação tornam a aula mais dinâmica, com diferentes interações, propiciando aproximações e vivências com a prática. 
As inovações pedagógicas contribuem para a mudança epistemológica docente e também para a mudança nas práticas e metodologias, possibilitando novos conhecimentos que despertem a curiosidade dos alunos e o interesse em aprender. Isso requer atualização e inovação por parte dos professores para que desenvolvam um trabalho de qualidade. "Penso que o conhecimento das inovações, tanto tecnológicas quanto pedagógicas, possibilita uma maior reflexão sobre nossas práticas e, consequentemente, qualificá-las”. (Estudante 82).

Os professores que utilizam as inovações a seu favor produzem alunos ativos, críticos e pensantes, os quais participam da aula e criam um ambiente favorável para aprendizagens mais significativas. Em seu depoimento, um estudante afirma: "As inovações contribuem para mudanças históricas que fazem a diferença e fazem com que surjam inquietações para levantar reflexões.” (Estudante 22). E Leite (2012) complementa:

Falar em inovação pedagógica pressupõe o rompimento com uma tradição. Mas se falamos em historicidade do conhecimento, memória, territorialidade não precisamos fazer rupturas epistemológicas, pois o conhecimento é histórico, a tradição/velho está sempre presente no novo. (LEITE, 2012, p. 8).

Com base nos estudos de Leite (2012), compreende-se que as inovações valorizam e acolhem a historicidade do conhecimento, a memória e a territorialidade. Nesses casos não há necessidade de ruptura, pois há um movimento da tradição com o novo, há respeito à tradição e à construção do conhecimento como um processo histórico em que o sujeito se constitui, reflete e se renova.

Nos pronunciamentos dos estudantes percebe-se que as inovações pedagógicas e tecnológicas estão presentes ao longo do curso, em um processo gradativo de construção de conhecimento, e que o curso apresenta inovações, pois remetem a ações que exigem criatividade e permitem o uso de novas ferramentas, tornando o curso mais dinâmico. "Muito importante o uso das tecnologias para as aprendizagens. Elas se tornam mais atrativas e dinâmicas como também acessíveis a todos”. (Estudante 4).

A utilização das tecnologias permite aos estudantes conhecerem e usufruírem desses meios tecnológicos e adquirir novas experiências. "Quanto às inovações tecnológicas, destaco: AVA, slides, vídeos. Considero muito produtivo o uso do AVA, pois é por meio dele que interagimos com nossos professores e colegas". (Estudante 43). As inovações tecnológicas, de acordo com as entrevistas, congregam também recursos mais modernos para auxiliar a interação e a aprendizagem, por exemplo, construções de blogs, vídeos, slides, videoconferências e jogos educativos on-line. "Inovações tecnológicas são recursos que 
podem e devem ser utilizados para agregar a prática pedagógica”. (Estudante 39). Nas práticas vivenciadas pelos depoentes na universidade são citados, como inovações tecnológicas, o AVA, com destaque para os recursos do fórum e do webfólio. Ambas as inovações tecnológicas e pedagógicas contribuem para qualificar o ensino e a aprendizagem e, de acordo com as falas de alguns estudantes, no que se refere às inovações tecnológicas, se destacam algumas disciplinas que ensinam a utilizar diferentes ferramentas e softwares que podem ser utilizados em sala de aula, na universidade e em escolas.

Métodos e conteúdos diferenciados vividos pelos estudantes correspondem às inovações pedagógicas percebidas ao longo do curso na universidade. "Cada professor utiliza sua prática em sala de aula, utilizando método que acredita ser mais adequado para sua turma. O mesmo ocorre na Universidade, onde passei por professores que utilizam dinâmicas, apoio tecnológico, suporte teórico, textos, seminários, rodas de conversa, etc". (Estudante 84). "O laboratório de Pedagogia também é um exemplo de inovação, pois a partir dele se pode tirar inúmeras ideias para pôr em prática". (Estudante 58). Observa-se a importância de oportunizar mudança da postura dos professores em sala de aula, percebida na prática, e também o apoio de diferentes espaços e recursos institucionais, sendo citado o Laboratório de Pedagogia, e que o pedagógico desse espaço agrega muito à formação acadêmica. De acordo com Cunha (2016, p. 8), “as inovações se materializam pelo reconhecimento de formas alternativas de saberes e experiências, nas quais se imbricam objetividade e subjetividade, senso comum e ciência, teoria e prática [...] procurando gerar novos conhecimentos".

Assim, as inovações pedagógicas e tecnológicas devem estar articuladas para aprimorar o processo de construção de ensino e aprendizagem. Ambas aprimoram a formação docente e devem propiciar novos conhecimentos. Salienta-se que para o fortalecimento das inovações pedagógicas e tecnológicas é fundamental o apoio institucional.

\section{c) Desafios e dificuldades na inserção das inovações pedagógicas e tecnológicas}

Observa-se, nos depoimentos dos estudantes do curso de Pedagogia, a presença de desafios e dificuldades na inserção das inovações pedagógicas e tecnológicas. Assim, destacam-se alguns pontos críticos citados por eles que merecem atenção por parte da Instituição: "É um bom curso, mas como na resposta um, sinto falta de mais disciplinas práticas". (Estudante 36). "O curso nos dá um suporte muito bom teoricamente, porém, em relação à prática, deve-se fazer modificações”. (Estudante 47).

Alguns dos depoimentos sinalizam a falta de algumas disciplinas práticas para que possa haver maior aproximação entre teoria e prática. Nóvoa (2017, p. 1.108) corrobora essa 
visão, ao dizer que, há alguns anos cresce "[...] um sentimento de insatisfação, que resulta da existência de uma distância profunda entre as nossas ambições teóricas e a realidade concreta das escolas e dos professores [...]". Concorda-se com Nóvoa (2017) e destaca-se que esse é um desafio a ser superado pelas instituições formadoras e pelas instituições escolares, de modo a aproximar o cotidiano educacional.

Os estudantes também dizem que ainda há pouco uso das tecnologias pelos professores. "Acredito que as principais dificuldades de inserção das inovações referem-se à falta de preparo para a utilização de diferentes tecnologias e em alguns momentos uma visão/concepção fechada de educação". (Estudante 80). Isso, em especial, quando os professores se limitam a usar somente data show em sala de aula, muitas vezes não ouvindo as contribuições dos alunos, permanecendo com uma postura tradicional. "Acredito que tudo que é novo num primeiro momento gera certa dificuldade. Precisamos estar sempre nos aperfeiçoando sobre os assuntos e sobre as tecnologias, para assim conseguir fazer uso dos mesmos". (Estudante 79). De acordo com Kenski (2012, p. 57), “os professores não são formados para o uso pedagógico das tecnologias, sobretudo as TIC. Nesse caso, [...] o professor usa a internet como se fosse apenas um grande banco de dados, para que os alunos façam 'pesquisa'."

Desse modo, o professor também precisa se adequar a essas inovações tecnológicas, entender para quê servem e quais os benefícios que elas podem proporcionar, além do modo correto e mais propício de usá-las, contribuindo para o processo de ensino e aprendizagem. Para alguns estudantes houve a dificuldade de se adaptarem ao AVA, ferramenta tecnológica utilizada pela universidade. Já outros veem o AVA como algo positivo e não se importam em se adaptar para utilizá-lo: "Muitas vezes tive de me adaptar às tecnologias como: drives, Skype, fórum, webfólio. (Estudante 61); "Devido ter algumas disciplinas semipresenciais, vários trabalhos ou a maioria são feitos através do uso de máquinas”. (Estudante 12); “A tecnologia e a informação andam muito rápido, é muito difícil acompanhar tudo”. (Estudante 33). De acordo com Kenski (2012, p. 105), a atividade docente, mediada pelas tecnologias, "é uma ação partilhada. Já não depende apenas de um único professor, isolado em sala de aula, mas das interações possíveis para o desenvolvimento das situações de ensino".

Desse modo, todas as partes envolvidas no processo de ensino e aprendizagem, interagindo juntas, em sintonia, fazendo cruzamentos e relações com as práticas cotidianas dos sujeitos envolvidos em tal debate, farão com que as descobertas e os aprendizados, citados pela autora, sejam de qualidade e constantes durante o cotidiano da sala de aula. 
Assim, aponta-se que as dificuldades e desafios citados pelos estudantes devem servir de reflexão para a superação, para a mudança, a fim de contribuir para as inovações.

\section{Considerações finais}

Adentrando na caminhada conclusiva desta investigação aponta-se sua importância por propiciar momentos de reflexão, estudos e análise do Curso de Pedagogia de uma universidade comunitária, além de gerar um espaço para os estudantes se expressarem, deixando nele seus depoimentos e contribuições. Os resultados apontam a relevância de a Universidade investir em uma formação que potencialize as inovações de modo a dar condições para que os estudantes construam novos conhecimentos e experiências durante sua formação, estabelecendo relações com a realidade educacional presente no cotidiano da atuação pedagógica.

A análise dos dados deu visibilidade ao processo de formação, em que a partilha de experiências entre os estudantes, acrescida da vivência com professores, proporcionou crescimento pessoal e profissional ao longo do curso. A aproximação com o novo, com a teoria, com a prática, com a pesquisa deu liberdade para questionar, problematizar e refletir criticamente, ampliando conhecimentos e saberes. Nesse âmbito, encontram-se presentes inovações pedagógicas relacionadas à metodologia e aos processos didáticos da aula que fortaleceram o diálogo, a pesquisa, a realização de dinâmicas e seminários que superaram as aulas expositivas. Além das inovações pedagógicas têm-se as inovações tecnológicas que possibilitaram a interação das tecnologias, confirmando a aprendizagem, com destaque para os recursos AVA - fórum e webfólio, vídeos, data show, dentre outras ferramentas e softwares. Ambas as inovações contribuíram para qualificar o processo de ensino e aprendizagem.

No entanto, também surgiram desafios e dificuldades que nortearam as trajetórias dos estudantes do Curso de Pedagogia, ressaltando-se algumas dificuldades: interações tecnológicas de estudantes junto ao AVA; distanciamento didático e pedagógico de alguns professores que ainda mantêm uma didática tradicional, com aulas pouco inovadoras.

Portanto, conclui-se que a universidade comunitária e o Curso de Pedagogia, investigados possibilitam a aproximação entre os estudos teóricos e as vivências práticas, havendo experiências com pesquisa, desenvolvimento de inovações pedagógicas e tecnológicas que contribuem qualitativamente para os processos de formação acadêmica. Porém, para a superação dos desafios e dificuldades encontrados aponta-se a importância de 
fortalecer a aproximação dos estudantes com as interações pedagógicas e tecnológicas, articuladas com as demandas educacionais e sociais; de fortalecer o processo de atualização e formação dos docentes atuantes no curso; e de uma visão institucional que vise à socialização do conhecimento, à formação humana, incorporada aos princípios democráticos e emancipatórios.

\section{REFERÊNCIAS}

ARROYO, M. Profissão de mestre. São Paulo: Cortez, 2004.

BOGDAN, R.; BIKLEN, S. Investigação qualitativa em educação: uma introdução à teoria e aos métodos. Trad. Porto Editora. Portugal: Porto, 1994.

BRASIL. Conselho Nacional de Educação. Resolução n. 1, de 15 de maio de 2006. Institui diretrizes curriculares nacionais para o curso de graduação em pedagogia, licenciatura. Diário Oficial da União, Brasília, 16 de maio de 2006, Seção 1, p. 11. Disponível em:

https://www.jusbrasil.com.br/diarios/576737/pg-11-secao-1-diario-oficial-da-uniao-dou-de16-05-2006. Acesso em: 23 jan. 2019.

BRASIL. Lei n. 12.881, de 12 de novembro de 2013. Dispõe sobre a definição, qualificação, prerrogativas e finalidades das Instituições Comunitárias de Educação Superior - ICES, disciplina o termo de parceria e dá outras providências. Diário Oficial da União, Brasília, 13 nov. 2013. Disponível em: http://www.planalto.gov.br/ccivil_03/_Ato20112014/2013/Lei/L12881.htm. Acesso em: 23 jan. 2019.

BRASIL. Ministério da Educação. Resolução CNE/CP 2, de 1 de julho de 2015. Conselho Nacional de Educação. Diretrizes curriculares nacionais para a formação inicial em nível superior (cursos de licenciatura, cursos de formação pedagógica para graduados e cursos de segunda licenciatura) e para a formação continuada.

CUNHA, M. I. Inovações na educação superior: impactos na prática pedagógica e nos saberes da docência. Em Aberto, Brasília, v. 29, n. 97, p. 87-101, set./dez. 2016.

FRANCO, M. A. S.; LIBÂNEO, J. C.; PIMENTA, S. G. As dimensões constitutivas da pedagogia como campo de conhecimento. Educação em Foco, Ano 14, n. 17, p. 55-78, jul. 2011. ISSN: 2317-0093. Disponível em:

http://revista.uemg.br/index.php/educacaoemfoco/index. Acesso em: 15 jan. 2019.

FREIRE, P. A educação na cidade. São Paulo: Cortez, 1991.

FREIRE, P. Pedagogia do oprimido. Rio de Janeiro: Paz e Terra, 2013.

KENSKI, V. M. Educação e tecnologias: o novo ritmo da informação. 8. ed. Campinas: Papirus, 2012. 
LEITE, D. Desafios para a inovação pedagógica na universidade do século 21. Revista da FAEEBA - Educação e Contemporaneidade, Salvador, v. 21, n. 38, p. 29-39, jul./dez. 2012.

MOROSINI, M. C. et al. A qualidade da educação superior e o complexo exercício de propor indicadores. Rev. Bras. Educ., Rio de Janeiro, v. 21, n. 64, p. 13-37, mar. 2016. Disponível em: http://www.scielo.br/scielo.php?script=sci_arttext\&pid=S1413-

24782016000100013\&lng=pt\&nrm=iso. Acesso em: 31 jan. 2019. DOI:

http://dx.doi.org/10.1590/S1413-24782016216402

NÓVOA, A. Firmar a posição como professor, afirmar a profissão docente. Cad. Pesqui., São Paulo, v. 47, n. 166, p. 1106-1133, dez. 2017. Disponível em:

http://www.scielo.br/scielo.php?script=sci_arttext\&pid=S0100-

15742017000401106\&lng=en\&nrm=iso. Acesso em: 31 jan. 2019.

NÓVOA, A. Para una formación de profesores construida dentro de la profesión. Revista de Educación, v. 350, p. 203-218, 2009. Disponível em:

http://www.revistaeducacion.mec.es/re350/re350_09.pdf. Acesso em: 05 mar. 2019.

PIMENTA, S. G. O Estágio na formação de professores: unidade teoria e prática? 11. ed. São Paulo: Cortez, 2012.

PIMENTA, S. G.; LIMA, M. S. L. Estágio e docência. São Paulo: Cortez, 2004.

PRETTO, N.; PINTO, C. C. Tecnologias e novas educações. Revista Brasileira de Educação, Rio de Janeiro, v. 11, n. 31, jan./abr. 2006. Disponível em:

http://www.scielo.br/pdf/rbedu/v11n31/a03v11n31.pdf. Acesso em: 08 nov. 2012.

SANTOS, B. S. A Universidade no século XXI: para uma reforma democrática e emancipatória da universidade. São Paulo: Cortez, 2004.

UNIVERSIDADE COMUNITÁRIA. Pró-Reitoria Acadêmica. Projeto Pedagógico - Curso de licenciatura em pedagogia. Rio Grande do Sul, 2014.

YIN, R. K. Estudo de caso: planejamento e método. 5. ed. Porto Alegre: Bookman, 2015.

\section{Como referenciar este artigo}

MORÉS, Andréia. Educação superior e formação de professores: inovações e desafios. Revista Ibero-Americana de Estudos em Educação, Araraquara, v. 15, n. 3, p. 1389-1407, jul./set. 2020. e-ISSN: 1982-5587. DOI: https://doi.org/10.21723/riaee.v15i3.13084

Submetido em: 19/08/2019

Revisões requeridas: $20 / 10 / 2019$

Aprovado em: 29/11/2020

Publicado em: 20/02/2020 